RESEARCH PAPER RP1545

Part of Journal of Research of the National Bureau of Standards, Volume 31, July 1943

\title{
WIDTH AND SPACING OF TENSILE CRACKS IN AXIALLY REINFORCED CONCRETE CYLINDERS
}

\author{
By David Watstein and Douglas E. Parsons
}

\section{ABSTRACT}

In a study of the spacing and width of tensile cracks, axially reinforced cylinders were tested by applying tensile forces to the reinforcement and observing the deformations of the concrete and the spacing and the width of cracks. The test data and theoretical equations were in good agreement with respect to the effects of the principal factors controlling the spacing and the width of cracks. The spacing and the width of cracks were found to depend chiefly on the ratio of the diameter to the percentage of reinforcement and the nature of the deformations on the bars. It is concluded that the use of a type of reinforcement bar that will afford more reliable anchorage would result in better control of cracking of reinforced concrete and economy in the use of reinforcement steel.

I. Introduction

II. Materials

1. Reinforcement bars

2. Concrete.

III. Reinforced tensile specimens _.

1. Description of specimens and strain gages

2. Method of testing

IV. Results of the tests and discussion

1. Widths of tensile cracks.

2. Spacing of cracks

3. Development of cracks in reinforced tensile specimens during testing:

4. Bond strength of the test bars

V. Theory of cracking of symmetrically reinforced concrete prisms subjected to axial forces

1. Scope and assumptions

2. Notation

3. Equations

(b) Evaluation of coefficients $\bar{K}_{1}$ and $\bar{K}_{2}$ for assumed distributions of stresses

(c) Cracking caused by shrinkage and change in temperature _......

(1) Members not restrained

(2) Members fully restrained

VI. Comments on the theory

VII. Comparison of test data with theory

VIII. Comparison with previous work

IX. Practical applications.

X. Summary of results.

XI. References 


\section{INTRODUCTION}

The avoidance of large cracks is one of the important considerations in the design of reinforced-concrete structures. It is this consideration which accounts for the use, in some structures, of reinforcement in excess of that needed for strength. Although this practice may result in the prevention of wide cracks, the same objective may be attained, with more economical use of reinforcement steel, if use is made of all means of minimizing cracking.

This paper deals with the factors governing the spacing and width of cracks in symmetrically reinforced concrete members subjected to axial tension. Tests of axially reinforced concrete cylinders are described, and the results of the tests are compared with the indications of theory and with the results of previous investigations.

The bond strengths of the test bars were determined with a supplementary series of pull-out specimens.

\section{MATERIALS \\ 1. REINFORCEMENT BARS}

The mechanical properties and the descriptions of the bars are given in table 1. The yield points were determined both by the "drop of the beam" and the "offset" methods, as described in ASTM Standards, Designation E 6-36.

TABLE 1.-Mechanical properties of the reinforcement bars

\begin{tabular}{|c|c|c|c|c|c|}
\hline Description of reinforcement bars ${ }^{1}$ & $\underset{\text { size }}{\text { Nominal }}$ & $\begin{array}{l}\text { Diameter as } \\
\text { determined } \\
\text { on basis of } \\
\text { weight per } \\
\text { unit of length }\end{array}$ & Yield point & $\begin{array}{l}\text { Tensile } \\
\text { strength }\end{array}$ & $\begin{array}{l}\text { Modulus of } \\
\text { elasticity }\end{array}$ \\
\hline $\begin{array}{l}\text { One plain, hot-rolled } \\
\text { One deformed } \\
\text { Two deformed. } \\
\text { One webbed, Isteg } \\
\text { One threaded }\end{array}$ & 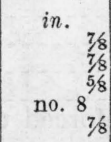 & in. $\begin{array}{r}0.87 \\
.87 \\
.62 \\
.95 \\
.80\end{array}$ & $\begin{array}{r}\text { lb. in. }{ }^{2} \\
39,000 \\
45,000 \\
47,000 \\
276,000 \\
275,000\end{array}$ & $\begin{array}{r}\text { lb./in. }{ }^{2} \\
61,000 \\
80,000 \\
75,000 \\
80,000\end{array}$ & $\begin{array}{l}\text { lb./in. }{ }^{2} \\
29,000,000 \\
29,500,000 \\
29,000,000 \\
25,000,000 \\
25,000,000\end{array}$ \\
\hline
\end{tabular}

1 The reinforcement bars are illustrated in figure 1.

${ }_{2}$ "Offset" $=0.2$ percent.

\section{CONCRETE}

Physical properties of the two different concrete mixes used in this study are given in table 2. The aggregates were Potomac River gravel and sand; the gravel ranged in size from no. 4 to $3 / 8$ in.

The test specimens used in determining the tensile strength of the concrete were 4 - by 16 -in. plain concrete cylinders. The procedure of preparing and testing the tensile specimens was that developed at the National Bureau of Standards and described in reference [1a]. ${ }^{1}$

TABLE 2.-Physical properties of the concrete

\begin{tabular}{|c|c|c|c|c|c|c|c|}
\hline Designation & $\begin{array}{l}\text { Propor- } \\
\text { tions, by } \\
\text { weight }\end{array}$ & $\begin{array}{c}\text { Cement } \\
\text { per cubic } \\
\text { yard of } \\
\text { concrete }\end{array}$ & $\begin{array}{c}\text { Water per } \\
\text { bag of } \\
\text { cement }\end{array}$ & Slump & $\begin{array}{l}\text { Compres- } \\
\text { sive } \\
\text { strength }\end{array}$ & $\begin{array}{l}\text { Tensile } \\
\text { strength, } \\
C_{m}\end{array}$ & $\begin{array}{c}\text { Modulus } \\
\text { of elas- } \\
\text { ticity in } \\
\text { tension, } \\
E_{0}\end{array}$ \\
\hline 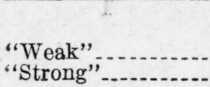 & $\begin{array}{l}1: 3.4: 3.6 \\
1: 1.5: 2.0\end{array}$ & $\begin{array}{r}\text { Bags } \\
5.4 \\
9.6\end{array}$ & $\begin{array}{l}\text { gal. } \\
9.5 \\
5.0\end{array}$ & $\begin{array}{l}\text { in. } \\
2.5 \\
2.0\end{array}$ & $\begin{array}{l}l b / \text { in }^{2} \\
12,900 \\
15,300\end{array}$ & $\begin{array}{rl}\text { lb/in. }{ }^{2} \\
2 \\
2 & 250 \\
2 & 450\end{array}$ & $\begin{array}{l}\text { lb/in. }{ }^{2} \\
2,900,000 \\
3,800,000\end{array}$ \\
\hline
\end{tabular}

${ }^{1}$ Average of 22 specimens.

2 Average of 3 specimens.

${ }_{1}$ Figures in brackets indicate the literature references at the end of this paper. 
Journal of Research of the National Bureau of Standards

Research Paper 1545
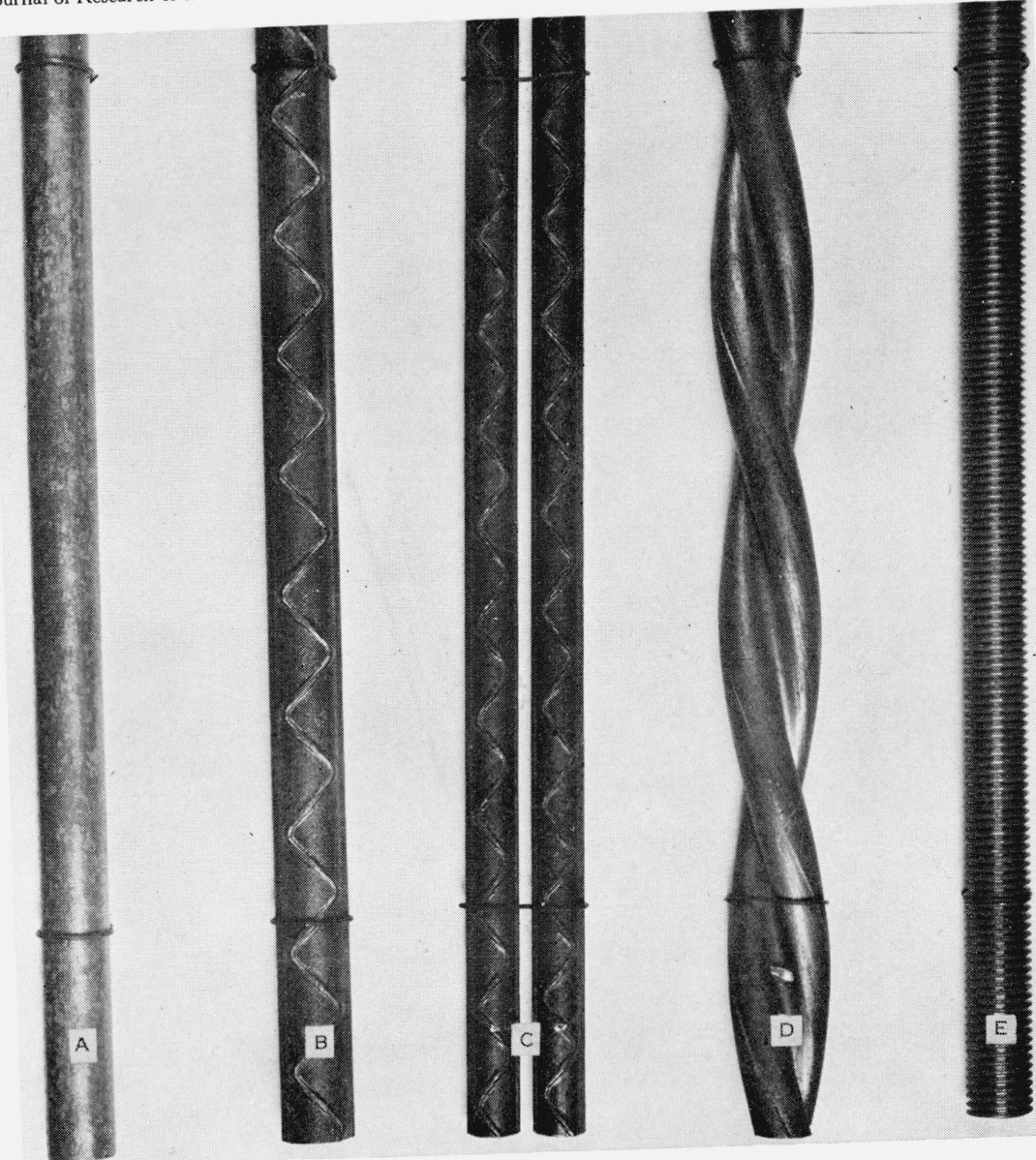

FIgURE 1.-Reinforcement bars.

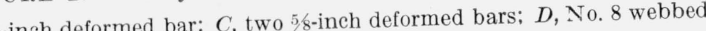
$A, 7 / 8$-inch plain hot-rolled bar; $B, 7 / 8$-inch deformed 7 Isteg bar; $E, 7 / 8$-inch threaded bar. 


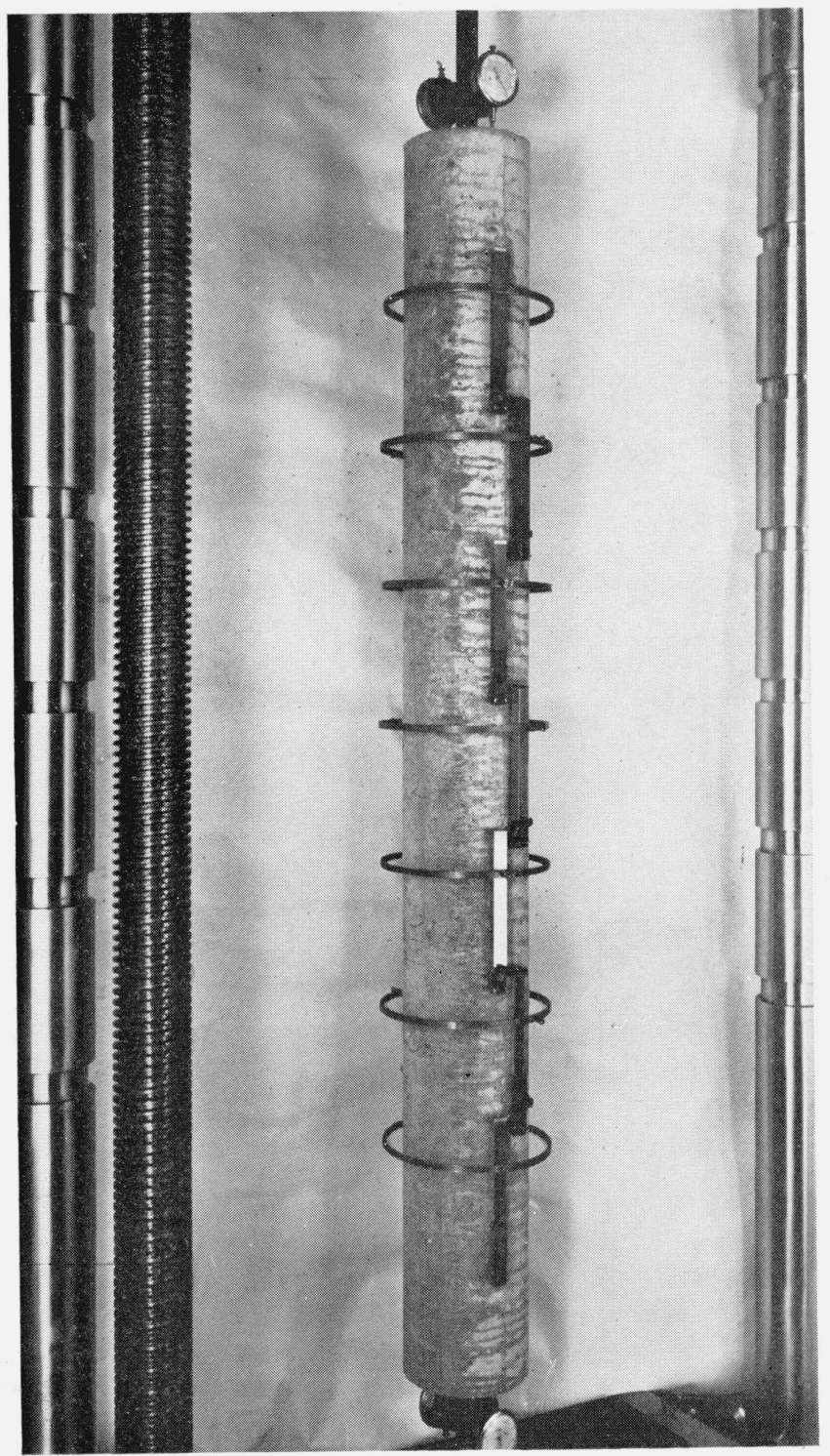

Figure 2.-Reinforced-concrete cylinder in tension. 


\section{REINFORCED TENSILE SPECIMENS}

\section{DESCRIPTION OF SPECIMENS AND STRAIN GAGES}

The specimens for the measurement of widths and spacing of cracks were cylinders $4 \mathrm{ft}$ long and $3 \frac{1}{2}, 4$, and 5 in. in diameter. They were reinforced with the five types of reinforcement bars shown in figure 1. The dimensions and percentages of reinforcement of the tensile cylinders are given in table 3 ; there were five similar cylinders corresponding to each type of specimen given in the table. The entire series of tests was made with both the "weak" and the "strong" concretes.

TABLE 3.-Dimensions and percentages of reinforcement of the tensile specimens

\begin{tabular}{|c|c|c|c|c|c|}
\hline \multirow{3}{*}{ Diameter of concrete cylinder } & \multicolumn{5}{|c|}{ Types of reinforcement bars } \\
\hline & $\begin{array}{c}\text { One } 7 / 8 \text { in. } \\
\text { plain }\end{array}$ & $\begin{array}{l}\text { One } 7 / 8 \text { in. } \\
\text { deformed }\end{array}$ & $\begin{array}{l}\text { Two } 5 / 8 \text { in. } \\
\text { deformed }\end{array}$ & $\begin{array}{l}\text { One No. } 8 \\
\text { webbed } \\
\text { Insteg }\end{array}$ & $\begin{array}{l}\text { One } 7 / 8 \text { in. } \\
\text { threaded }\end{array}$ \\
\hline & \multicolumn{5}{|c|}{ Percentage of reinforcement } \\
\hline \multicolumn{6}{|l|}{ in. } \\
\hline 5 & $\begin{array}{l}4.8 \\
2.9\end{array}$ & $\begin{array}{l}4.8 \\
2.9\end{array}$ & $\begin{array}{l}4.9 \\
3.0\end{array}$ & $\begin{array}{l}5.7 \\
3.5\end{array}$ & $\begin{array}{l}4.0 \\
2.4\end{array}$ \\
\hline
\end{tabular}

The tensile strain on the surface of the test specimens and, subsequent to failure of concrete, the widths of tensile cracks were measured with fourteen 6-in. Tuckerman gages arranged in pairs along diametrically opposite lines. The elongation indicated by a pair of opposite strain gages bridging a given crack was taken as a measure of the width of the crack. Seven gages on each side of the specimen overlapped $1 / 2$ in., thus covering a continuous length of $39 \mathrm{in}$. (see fig. 2). The gages bore on brass strips cemented to the surface of the concrete cylinders; the strips were $1 / 8 \mathrm{in}$. wide in the direction of the axis of the cylinder. Although the few cracks which appeared outside this gaged length were not measured, they were taken into account in estimating the average spacing of cracks.

The Tuckerman gages used in measuring the widths of cracks are highly sensitive and have a range of only 0.005 in.; consequently, they had to be reset several times during a test. While this was a disadvantage, the Tuckerman gages were selected, since they required no inserted gage points in the concrete, which might have produced objectionable planes of weakness in the concrete cylinders. Another advantage of the Tuckerman gages was the rapidity with which strain readings could be obtained.

\section{METHOD OF TESTING}

All reinforced tensile specimens were tested in a 60,000-lb capacity fluid-support, Bourdon-tube, hydraulic machine. The load was applied to the bar, which extended about 18 in. beyond each of the faces of the cylinder. In the case of specimens reinforced with a pair of $5 / 8$-in. deformed bars spaced 2 in. apart, the load was applied to the threaded ends of the test bars through a 2 - by 2 - by 4 -in. cross block, 
which in turn was loaded by means of a threaded $7 / 8$-in. bar passing through the center of the cross block.

An initial load of about $200 \mathrm{lb}$ was applied and maintained while the gages were mounted on the specimen. The load was then applied in increments of about $2,000 \mathrm{lb}$ until several tensile cracks were observed. Thereafter, the increments of load were increased to 3,000 or $4,000 \mathrm{lb}$, depending on the number of cracks and the expected maximum load.

In testing specimens with plain and deformed bars the load was applied up to the yield point of the steel; the threaded bars were stressed up to $60,000 \mathrm{lb} / \mathrm{in}^{2}$, and the somewhat larger webbed Isteg bars were stressed up to $50,000 \mathrm{lb} / \mathrm{in}^{2}{ }^{2}$

\section{RESULTS OF THE TESTS AND DISCUSSION}

\section{WIDTHS OF TENSILE CRACKS}

The graphs in figures 3 and 4 show the relation between widths of cracks and the corresponding stresses in the free ends of the reinforcing bars. The widths of cracks were proportional to the stress above the value designated as "the stress at zero width of crack," obtained by extrapolation. Most of the values of the crack widths plotted are the average values for five similar specimens for each type of bar. In several instances, the data represent fewer than five similar specimens, since those for several specimens were discarded in view of the uncertainty in strain gage readings or the erratic formation of tensile cracks.

Since the different test bars were not all of the same size, the effects of shape and surface roughness of bars on widths of cracks may be estimated more readily after adjusting these values for the differences in percentages of reinforcement. Accordingly, the data in figure 5 for the percentages of reinforcement shown were obtained from figure 3 and 4 by interpolation.

The graphs in figure 5 show that, for equal stresses in the steel, specimens reinforeed with pairs of $5 / 8$-in. deformed bars and those with threaded bars developed cracks of the smallest widths. At a stress of $30,000 \mathrm{lb} / \mathrm{in} .^{2}$, the width of cracks in specimens with threaded bars were from 41 to 52 percent of the corresponding width in specimens reinforced with plain hot-rolled bars, whereas for the double $5 / 8$-in. deformed bars this ratio ranged from 45 to 51 percent. At the same stress, the ratio of widths of cracks in specimens reinforced with double $5 / 8$-in. deformed bars to corresponding values for $7 / 8$-in. deformed bars ranged from 59 to 63 percent for "weak" concrete specimens and from 68 to 80 percent for specimens of "strong" concrete. The crosssectional areas of a parr of $5 / 8$-in. deformed bars and one $7 / 8$-in. deformed bar were nearly equal, but the ratio of their perimeters was 0.70 . There was no significant difference in the widths of cracks developed by specimens with $7 / 8$-in. deformed bars and No. 8 webbed Isteg bars.

Referring again to figure 5, the stresses corresponding to a given width of crack were greater for the threaded and $5 / 8$-in. deformed bars than for the others. In particular, for the width of crack in specimens reinforced with plain hot-rolled bars carrying a stress of $20,000 \mathrm{lb} / \mathrm{in} .{ }^{2}$, the stresses in the other bars were, on the average, $24,000 \mathrm{lb} / \mathrm{in} .{ }^{2}$ with the Isteg bars, $25,000 \mathrm{lb} / \mathrm{in}^{2}{ }^{2}$ with the $7 / 8$-in deformed bars and 35,000 $\mathrm{lb} / \mathrm{in}^{2}$ with the threaded and the $5 / 8$-in. deformed bars. 
Comparison of the results obtained with the "weak" and the "strong" concretes indicate no appreciable difference in the width of cracks for stresses in the reinforcement corresponding to commonly used design values. It was also observed that the relative standing

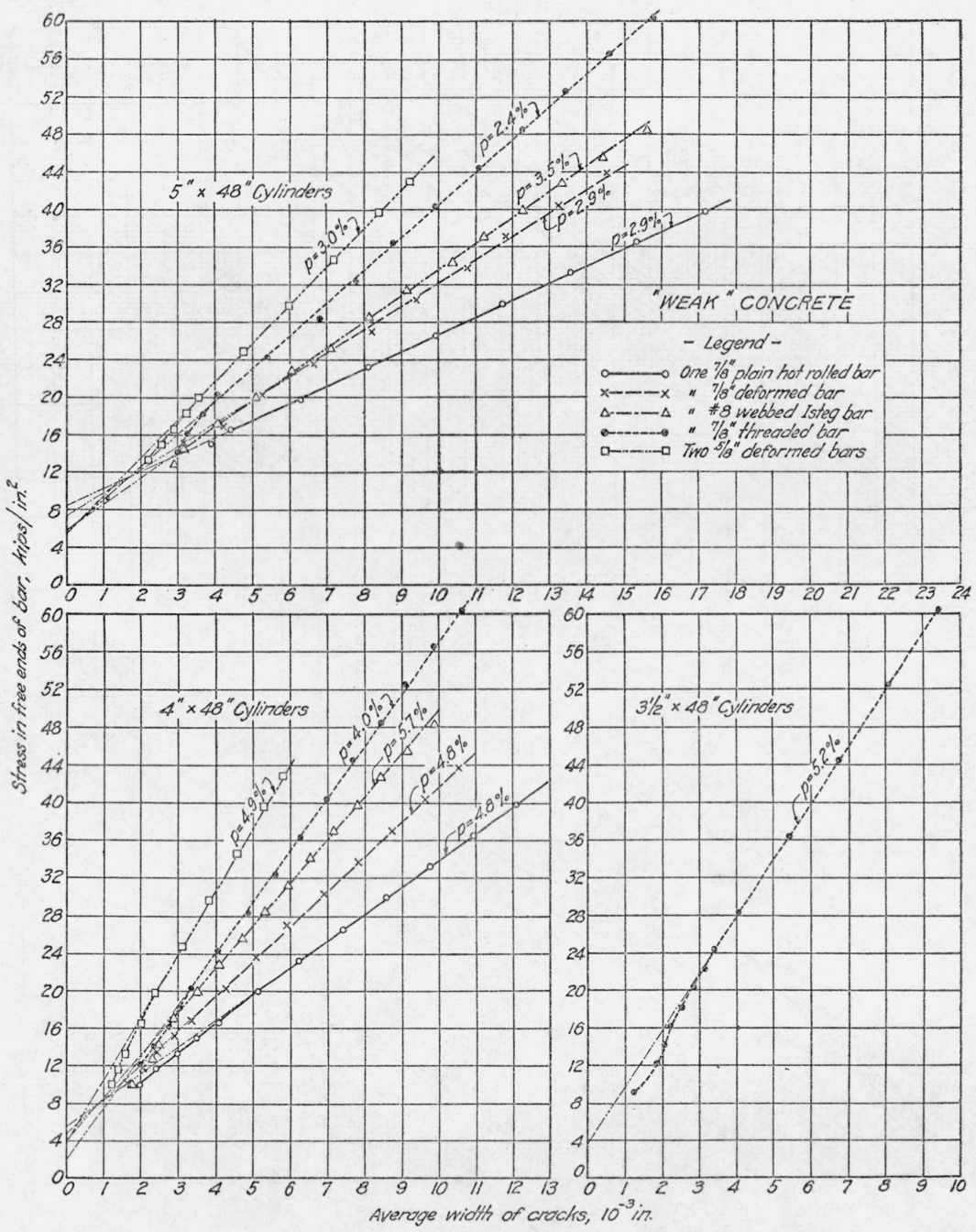

Figure 3.-Widths of tensile cracks observed in reinforced cylinders of "weak" concrete.

$1 \mathrm{kip}=1,000 \mathrm{lb} ; p=$ percentage of reinforcement.

of the various types of bars remained substantially the same for the two concretes.

Several 4- and 5-in. cylinders of "weak" concrete, each reinforced with a smooth, cold-rolled steel bar, were tested (the data are not given in detail). The 4-in. cylinders developed one crack each, while the 5 -in. cylinders did not crack when the steel was stressed to 60,000 
lb/in. ${ }^{2}$ Unlike the cracks in other specimens, the width of cracks for cold-rolled bars did not vary linearly with the stress in the steel; rather, the rate of widening of the cracks with load became smaller as the stress in the steel increased. Measurements on the surface of the

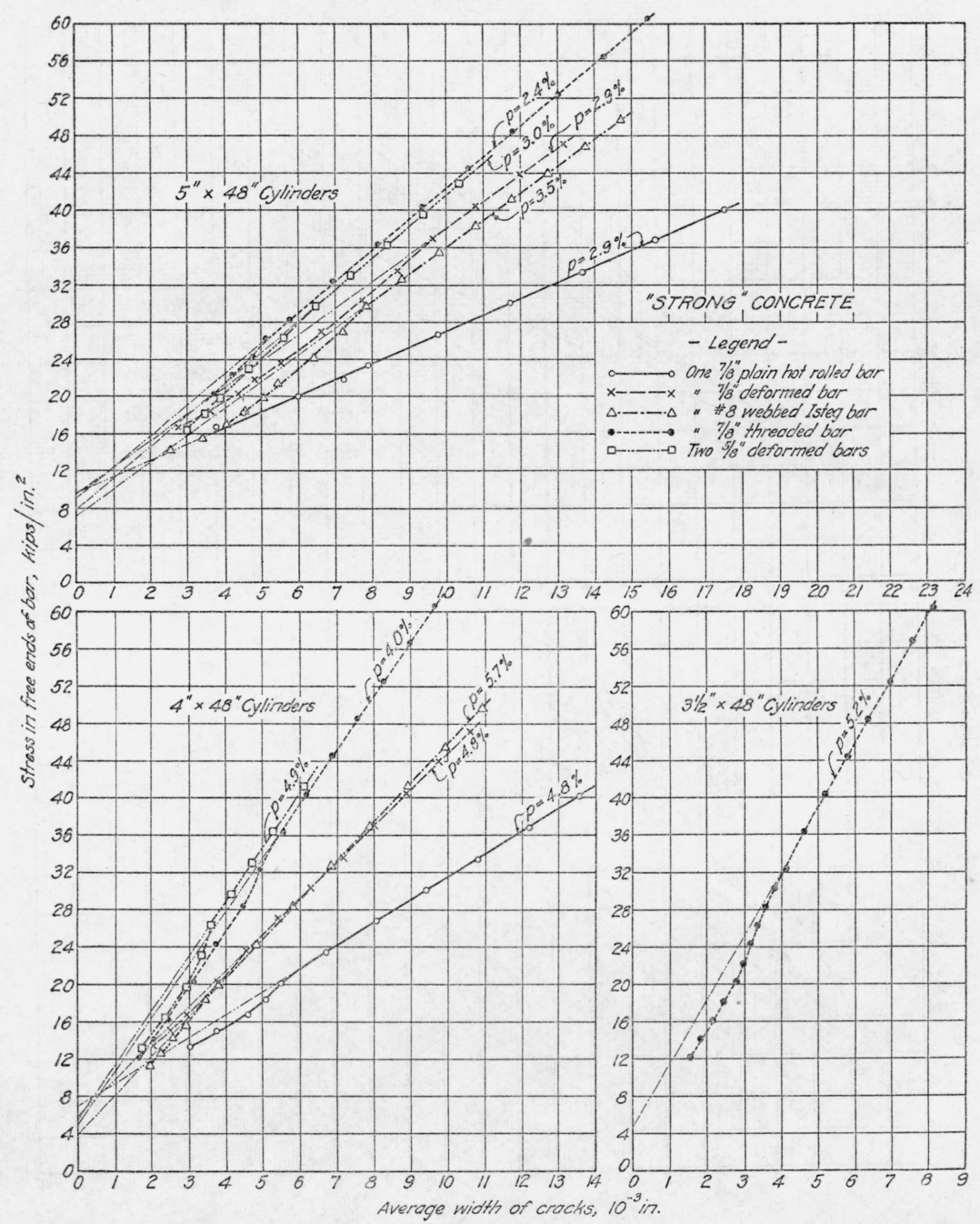

FIGURE 4.-Widths of tensile crarks observed in reinforced cylinders of "strong" concrete.

$1 \mathrm{kip}=1,000 \mathrm{lb} ; p=$ percentage of reinforcement.

5- by 48-in. uncracked cylinders indicated a sharply defined maximum tensile strain at a stress of about $16,000 \mathrm{lb} / \mathrm{in}^{2}{ }^{2}$; as the stress in the steel was further increased, the tensile strain in the concrete began to fall off rapidly.

The observed behavior of the cold-rolled bar points to progressive break-down of bond as the stress in the steel increases; that is, the 
bond is first destroyed at the point where the bar enters the concrete and as the stress increases the break-down of bond progresses along the reinforcement until the bond is practically destroyed along the entire embedded bar. This interpretation of the results is in agree-

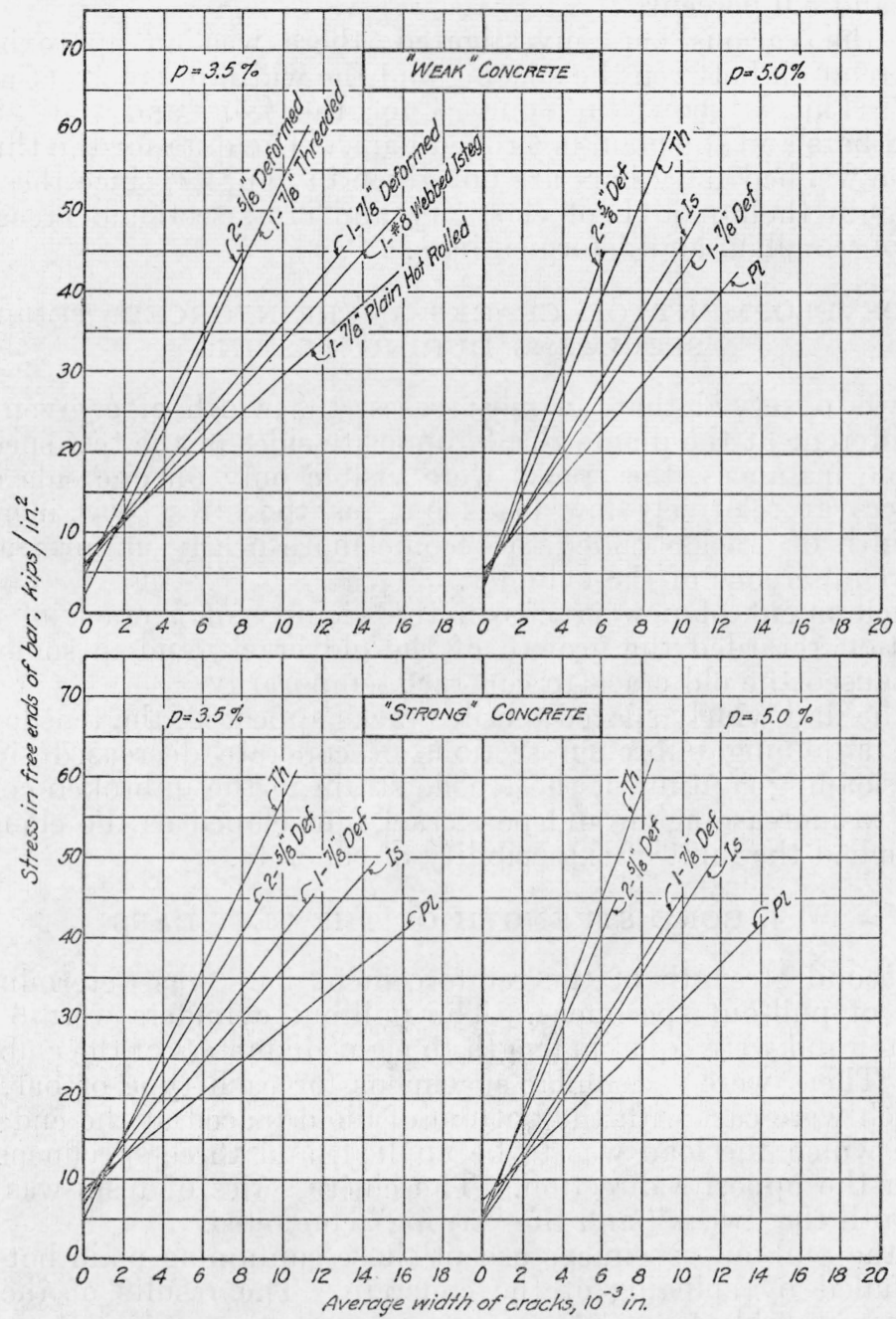

FIGURE 5.-Widths of tensile cracks interpolated to correspond to cylinders with reinforcement of 3.5 and 5.0 percent.

$1 \mathrm{kip}=1,000 \mathrm{lb}$.

ment with data on tests of smooth steel embedded in pull-out specimens reported by Glanville [1], Watstein [2], and Gilkey, et al. [3]. Gilkey, in particular, observed that in 48-in. pull-out specimens the bond stress at the loaded end of the bar began to decrease before there was any stress in the steel at a point $12 \mathrm{in}$. from the loaded end. 


\section{SPACING OF CRACKS}

The spacing of cracks for the five types of bars in specimens of both "weak" and "strong" concrete is shown in figure 6, adjusted by interpolation to correspond to specimens having reinforcement of 3.5 and 5.0 percent.

For the various bars investigated, there was an approximately linear relation between the spacing and the width of cracks at a given stress. This is shown in figure 7 for the $5 / 8$-in. and the $7 / 8$-in. deformed bars and the plain hot-rolled bars. The data for the threaded and the webbed Isteg bars are not given in figure 7 , since these bars differed in their moduli of elasticity and cross-sectional areas from those of the plain and deformed bars.

\section{DEVELOPMENT OF CRACKS IN REINFORCED TENSILE SPECIMENS DURING TESTING}

It was observed that, in most cases, the width of a given crack was different at the diametrically opposite sides of the test specimen. In some instances, the cracks were visible only on one side of the cylinders at relatively low loads but, as the stress was increased, the width of cracks tended to become more nearly uniform around the circumference of the cylinder.

Development of new cracks in the vicinity of a crack of earlier formation retarded the growth of the old crack, and in some cases even caused the old crack to contract temporarily.

As the first widely spaced tensile cracks appeared, the tensile strain in the adjoining unbroken sections of concrete decreased sharply; as the loading continued, the tensile strain in the unbroken concrete began to increase again and new cracks developed as the elongation approached the limit of extensibility of concrete.

\section{BOND STRENGTH OF THE TEST BARS}

The bond strength of the reinforcement bars was determined by means of pull-out specimens. The pull-out cylinders were 6 in. in diameter and were equal in length to eight diameters of the embedded bars. There were six similar specimens for each type of bar, three of which were cast with the bottom of mold placed at the end of the bar to which the load was to be applied, and three specimens were cast in the opposite direction. The entire series of tests was made with both the "weak" and the "strong" concretes.

All the pull-out specimens except those containing plain hot-rolled steel failed by splitting of the concrete, The results of the tests are given in table 4 . 


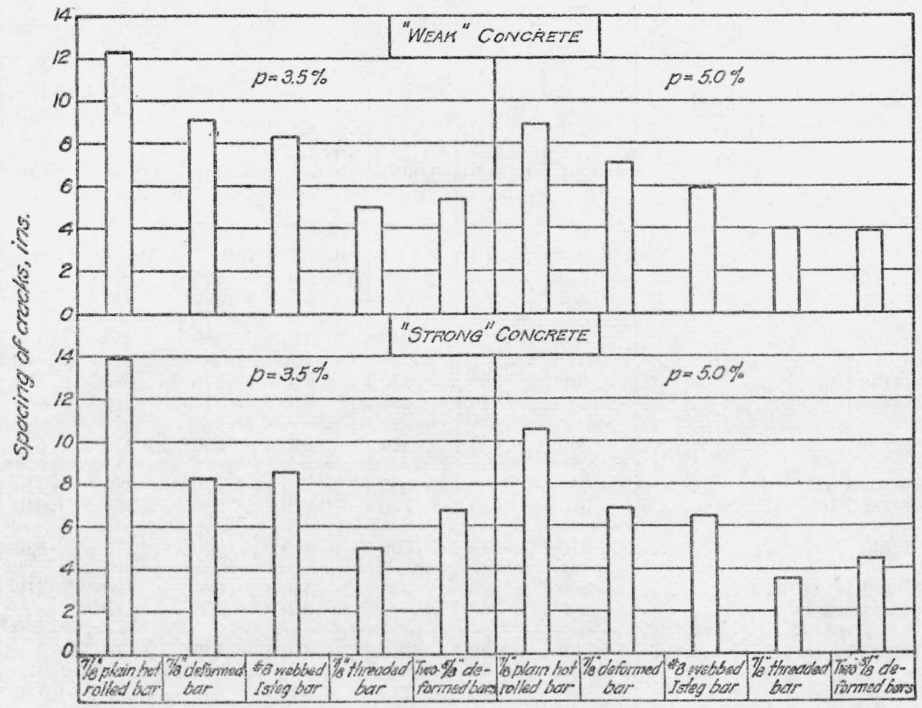

FigURE 6.-Spacing of tensile cracks interpolated to correspond to cylinders with reinforcement of 3.5 and 5.0 percent.

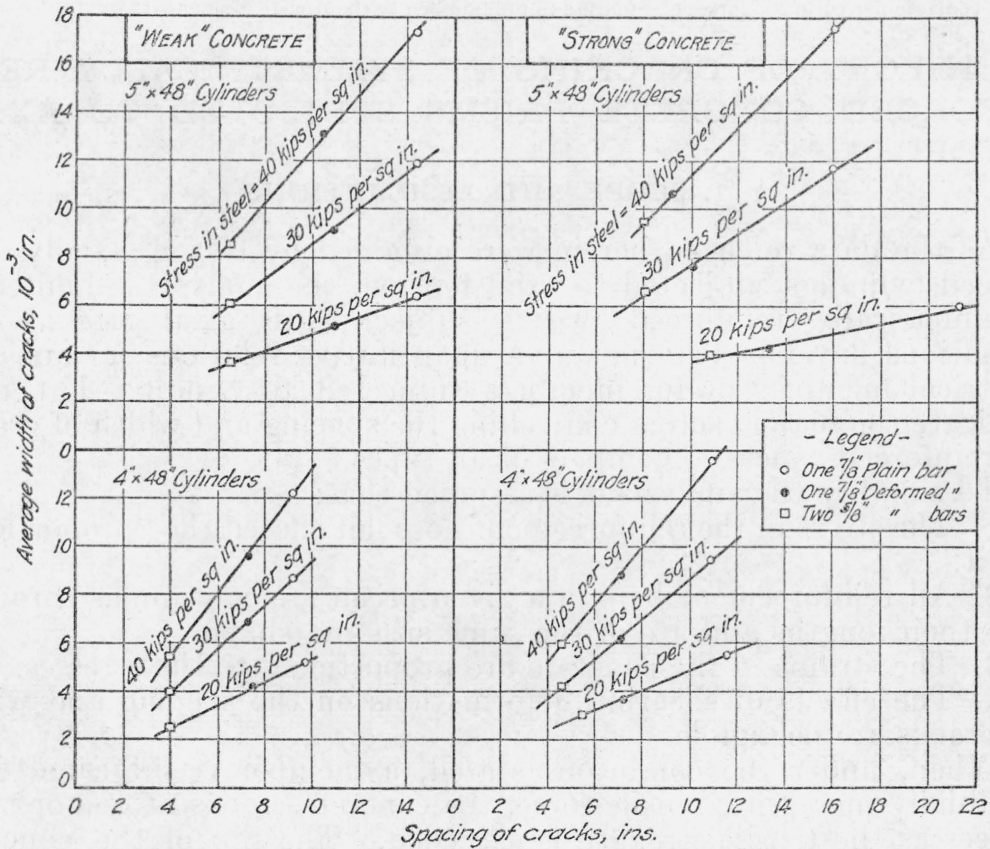

FIGURE 7.-Relation of widths of cracks to spacing observed in cylinders reinforced with bars of various types. 
TABLE 4.-Bond strength of test bars

\begin{tabular}{|c|c|c|c|c|c|c|c|c|}
\hline \multirow{3}{*}{$\begin{array}{l}\text { Bar and direction of pull } \\
\text { during test } 1\end{array}$} & \multicolumn{4}{|c|}{ "Weak" concrete } & \multicolumn{4}{|c|}{ "Strong" concrete } \\
\hline & \multicolumn{3}{|c|}{$\begin{array}{c}\text { Bond stress at end } \\
\text { slip of - }\end{array}$} & \multirow{2}{*}{$\begin{array}{c}\text { Bond } \\
\text { strength }\end{array}$} & \multicolumn{3}{|c|}{$\begin{array}{c}\text { Bond stress at end } \\
\text { slip of- }\end{array}$} & \multirow{2}{*}{$\begin{array}{l}\text { Bond } \\
\text { strength }\end{array}$} \\
\hline & $\begin{array}{l}0.0001 \\
\text { in. }\end{array}$ & $\begin{array}{l}0.0005 \\
\text { in. }\end{array}$ & $\begin{array}{l}0.0010 \\
\text { in. }\end{array}$ & & $\begin{array}{l}0.0001 \\
\text { in. }\end{array}$ & $\begin{array}{l}0.0005 \\
\text { in. }\end{array}$ & $\begin{array}{l}0.0010 \\
\text { in. }\end{array}$ & \\
\hline $\begin{array}{l}7 / 8 \text { in. plain }(d) \\
7 / 8 \text { in. plain }(0) \ldots\end{array}$ & $\begin{array}{r}l b / \text { in }^{2} \\
240 \\
210\end{array}$ & $\begin{array}{r}l b / \text { in. } .^{2} \\
330 \\
280\end{array}$ & $\begin{array}{r}l b / \text { in }^{2}{ }^{2} \\
360 \\
310\end{array}$ & $\begin{array}{r}\text { lb/in.2 } \\
440 \\
370\end{array}$ & $\begin{array}{r}l b / \text { in }^{2} \\
140 \\
250\end{array}$ & $\begin{array}{r}l b / \text { in }^{2} \\
190 \\
330 \\
\end{array}$ & $\begin{array}{r}\text { lb/in. } \\
220 \\
380\end{array}$ & $\begin{array}{r}l b / \text { in }^{2} \\
\quad 450 \\
560\end{array}$ \\
\hline Average... & 230 & 300 & 340 & 410 & 200 & 260 & 300 & 510 \\
\hline $\begin{array}{l}7 / 8 \text { in. deformed }(\mathrm{d}) \text {-. } \\
7 / 8 \text { in. deformed }(0)-.\end{array}$ & $\begin{array}{l}190 \\
220\end{array}$ & $\begin{array}{l}290 \\
410\end{array}$ & $\begin{array}{l}330 \\
490\end{array}$ & $\begin{array}{l}810 \\
870\end{array}$ & $\begin{array}{l}240 \\
210\end{array}$ & $\begin{array}{l}320 \\
510\end{array}$ & $\begin{array}{l}370 \\
680\end{array}$ & $\begin{array}{l}1,210 \\
1,410\end{array}$ \\
\hline A verage . - & 200 & 350 & 410 & 840 & 220 & 410 & 520 & 1,310 \\
\hline $\begin{array}{l}5 / 8 \text { in. deformed (d) } \ldots . . \\
5 / 8 \text { in. deformed (o) } \ldots\end{array}$ & $\begin{array}{l}360 \\
370\end{array}$ & $\begin{array}{l}560 \\
670\end{array}$ & $\begin{array}{l}600 \\
790 \\
\end{array}$ & $\begin{array}{l}770 \\
910\end{array}$ & $\begin{array}{l}220 \\
380\end{array}$ & $\begin{array}{l}280 \\
860\end{array}$ & $\begin{array}{r}310 \\
1,040 \\
\end{array}$ & $\begin{array}{r}670 \\
1,160\end{array}$ \\
\hline A verage.... & 370 & 610 & 700 & 840 & 300 & 570 & 680 & 910 \\
\hline $\begin{array}{l}\text { No. } 8 \text { webbed Isteg (d) } \\
\text { No. } 8 \text { webbed Isteg (o) }\end{array}$ & $\begin{array}{l}300 \\
290\end{array}$ & $\begin{array}{l}500 \\
350\end{array}$ & 530 & $\begin{array}{l}540 \\
360\end{array}$ & $\begin{array}{l}380 \\
500\end{array}$ & $\begin{array}{l}490 \\
670\end{array}$ & 510 & $\begin{array}{l}560 \\
680\end{array}$ \\
\hline Average... & 290 & 430 & -... & 440 & 440 & 580 & n. & 620 \\
\hline $\begin{array}{l}\text { 7/8 in. threaded }(d) \\
7 / 8 \text { in. threaded }(0) \ldots\end{array}$ & $\begin{array}{l}490 \\
660\end{array}$ & $\begin{array}{l}660 \\
980\end{array}$ & 770 & $\begin{array}{l}1,080 \\
1,380\end{array}$ & $\begin{array}{l}640 \\
650\end{array}$ & $\begin{array}{l}1,000 \\
1,600\end{array}$ & 1,180 & $\begin{array}{l}1,740 \\
2,010\end{array}$ \\
\hline Average. . & 570 & 820 & . & 1,230 & 650 & 1,300 & & 1,870 \\
\hline
\end{tabular}

1 Specimens with concrete placed in the direction of pull applied to the bar are designated (d); specimens with concrete placed in the direction opposite to pull applied to the bar are designated $(0)$.

\section{THEORY OF CRACKING OF SYMMETRICALLY REIN- FORCED CONCRETE PRISMS SUBJECTED TO AXIAL FORCES}

\section{SCOPE AND ASSUMPTIONS}

As the data reported herein were obtained by testing axially reinforced cylinders subjected to axial tension, the analysis is limited to symmetrically reinforced prisms subjected to axial stress. The equations developed do not give quantitative relations for nonsymmetrical members or for members subjected to bending, but they indicate the major factors controlling the spacing and width of cracks in reinforced-concrete members of all types.

To simplify the analysis it is assumed that:

1. The stress in the reinforcement does not exceed the "proportional limit."

2. All reinforcement bars in a given prism are continuous throughout their lengths and are of the same size and shape.

3 . The strains in the concrete are proportional to the stresses.

4. The effects of shearing deformations on the spacing and width of cracks are negligible.

When, under the conditions stated, a member is subjected to a gradually increasing tensile force, the concrete cracks at one or more places as the tensile strength is exceeded. The slip of the concrete on the reinforcement relieves the stress in portions of the concrete adjacent to cracks, and the tensile stress in the concrete is only that induced by the bond stresses. The distribution of the tensile stress 
depends upon the distribution of the bond stress along the reinforcement, which in turn depends upon the amount of slip and the stress in the reinforcement.

Regardless of the distribution of the stresses after the first cracking, the number of cracks increase until, because of excessive slip and reduction of length between cracks, the stress in the concrete does not again exceed the tensile strength. Then, the cracks become wider as the tensile stress in the reinforcement increases, but the spacing of the cracks remains constant. Present consideration will be limited to the conditions existing after cracking.

\section{NOTATION}

$A_{c}=$ cross-sectional area of the concrete.

$N=$ number of reinforcement bars in the area $A_{c}$.

$A_{s}=\frac{N \pi D^{2}}{4}$ (cross-sectional area of thereinforcementin the area $\left.A_{c}\right)$.

$D=\sqrt{\frac{4 A_{s}}{N \pi}}$ (diameter of round bar having an area of $\left.A_{s} / N\right)$.

$C=$ average tensile stress in the concrete at any cross section.

$C_{m}=$ tensile strength of the concrete.

$E_{c}=$ modulus of elasticity of concrete.

$E_{s}=$ modulus of elasticity of reinforcement.

$f_{s}=$ tensile stress in reinforcement at a crack.

$K_{1}, K_{2}=$ dimensionless coefficients, the values of which depend upon the distribution of bond stress.

$L=$ spacing of tensile cracks (axial distance between adjacent cracks).

$n=\mathrm{E}_{s} / \mathrm{E}_{c}$.

$p=A_{s} / A_{c}$. (ratio of reinforcement).

$u=$ bond stress (calculated as for a round bar, that is, a bar having a perimeter equal to $\pi D$ ).

$u_{m}=$ maximum bond stress.

$R=u_{m} / C_{m}$ (ratio of bond strength to tensile strength of the concrete-an index of the bonding efficiency of the reinforcement).

$S=$ tensile stress in the reinforcement at any cross section.

$T=$ increase in temperature of member (assumed uniformly distributed).

$V=$ shrinkage of concrete per unit of length, if not restrained.

$W=$ average width of tensile cracks in the concrete.

$x=$ distance from a crack, measured along reinforcement.

$Z_{c}=$ coefficient of thermal expansion of concrete.

$Z_{s}=$ coefficient of thermal expansion of reinforcement.

$P=\mathrm{N} \pi D$ (summation of perimeters of bars in the area $A_{c}$ ).

$s=$ slip per unit of length between concrete and reinforcement. $e=$ extensibility of concrete.

\section{EQUATIONS}

(a) GENERAL

At a distance $x$ from a crack $\left(0<x<\frac{L}{2}\right)$ the tensile stress in the con- 
crete equals the force transmitted by bond divided by the area of the concrete, that is,

$$
C=\frac{P}{A_{c}} \int_{0}^{x} u d x=\frac{4 p}{D} \int_{0}^{x} u d x .
$$

Similarly, the stress in the reinforcement is given by

$$
S=f_{s}-\frac{P}{A_{s}} \int_{0}^{x} u d x=f_{s}-\frac{4}{D} \int_{0}^{x} u d x .
$$

The tensile stress in the concrete may reach its maximum value only at $x=L / 2$, or the maximum value may be approximately constant over a considerable length during the early stages of cracking. However, as cracking continues, the spacing of the cracks becomes smaller until a limiting value of spacing is reached at which the tensile stress does not exceed the tensile strength of the concrete. From eq 1 the maximum stress in the unbroken portion of concrete of length $L$ is

$$
C_{m}=\frac{4 p}{D} \int_{0}^{L / 2} u d x
$$

from which an estimate of the minimum spacing of cracks, $L$, may be found if the distribution of the bond stress is known.

The total elongation of the concrete per unit of length for any value of $x$ is the sum of deformations resulting from stress, shrinkage, and change in temperature, that is

$$
C / E_{c}-V+T Z_{c}
$$

Similarly, the elongation of the reinforcement is

$$
S / E_{s}+T Z_{s} \text {. }
$$

The slip per unit of length, between the concrete and the reinforcement, is the difference between the elongations per unit of length of the reinforcement and of the concrete, or

$$
s=\frac{S-n C}{E_{s}}+V+T\left(Z_{s}-Z_{c}\right)
$$

The average width of crack is the summation of the slip per unit of length between two adjacent cracks, or

$$
W=2 \int_{0}^{L / 2} s d x .
$$

Equations 3 and 5 may be solved to find the spacing and width of cracks if the form of distribution of the bond stress is known. However, the actual distribution of bond stress cannot be predicted with accuracy. The evidence available [1, 2, 3] indicates that it varies with the amount of slip, the shape or surface roughness of the reinforcement, and the nature of the forces acting on the member. Nevertheless, general solutions indicate the relations of the various factors, and a few particular solutions show the nature of the effect of variations of the distribution of stresses.

To find the minimum spacing of cracks, $L$, let $u=u_{m} f(x / L)$. Then

$$
\int_{0}^{L / 2} u d x=u_{m} \int_{0}^{L / 2} f\left(\frac{x}{L}\right) d x=u_{m} L \int_{0}^{1 / 2} f(X) d X
$$


in which $X=x / L$.

Inserting this in eq 3 and solving for $L$ give

in which

$$
L=\frac{K_{1} C_{m} D}{u_{m} p}=\frac{K_{1} D}{R p}
$$

$$
K_{1}=\frac{1}{4 \int_{0}^{1 / 2} f(X) d X} .
$$

Substituting from eq 1, 2, 4, and 6 and integrating eq 5 give for the width of cracks, $W$,

Or

$$
W=L\left[V+T\left(Z_{s}-Z_{c}\right)+\frac{f_{s}}{E_{s}}-\frac{K_{2} C_{m}}{E_{s}}\left(\frac{1}{p}+n\right)\right] .
$$

$$
W=\frac{K_{1} D}{R p}\left[V+T\left(Z_{s}-Z_{c}\right)+\frac{f_{s}}{E_{s}}-\frac{K_{2} C_{m}}{E_{s}}\left(\frac{1}{p}+n\right)\right],
$$

in which $K_{2}$ is found by the method used to obtain $K_{1}$ and is given by

$$
K_{2}=8 K_{1} \int_{0}^{1 / 2} d X \int_{0}^{X} f(X) d X .
$$

(b) EVALUATION OF COEFFICIENTS $K_{1}$ AND $K_{2}$ FOR ASSUMED DISTRIBUTIONS OF STRESSES

An indication of the effects of variations in the distribution of the bond stress may be obtained by calculating values of $K_{1}$ and $K_{2}$ for assumed forms of $u=u_{m} f(x / L)$. Three of these forms are illustrated in figure 8, each one of which may be considered as a rough approximation of a possible distribution of stresses. Calculated values of $K_{1}$ and $K_{2}$ are as follows:

$\begin{array}{cccc}\text { Assumption } & \text { I } & \text { II } & \text { III } \\ K_{1}=\ldots \ldots & 1 / 2 & 3 / 4 & 1.0 \\ K_{2}=\ldots \ldots \ldots & 1 / 2 & 5 / 8 & 2 / 3\end{array}$

Although the distribution of stress in case I is physically impossible, it was included in the discussion, since it is often assumed by designers for the sake of simplicity.

(c) CRACKING CAUSED BY SHRINKAGE AND CHANGE IN TEMPERATURE

(1) Members not restrained.-For members not restrained by external forces, $f_{\mathrm{s}}=0$, and equation $8 \mathrm{a}$ may be written

$$
W=\frac{K_{1} D}{R p}\left[V+T\left(Z_{s}-Z_{c}\right)-\frac{K_{2} C_{m}}{E_{s}}\left(\frac{1}{p}+n\right)\right] .
$$

For these members the stresses are induced by differential length changes between the concrete and the reinforcement. Before the concrete cracks, the force in the concrete, $C A_{c}$, is equal and opposite to that in the reinforcement, $S A_{s}$, and the deformations are equal. By equating expressions $3 \mathrm{a}$ and $3 \mathrm{~b}$ and expressing $S$ in terms of $C$, the tensile stress in the concrete is given by

$$
C=\frac{E_{s} p}{1+p n}\left[V+T\left(Z_{s}-Z_{c}\right)\right]
$$


the concrete will not crack until $C=C_{m}$, the tensile strength.

(2) Members fully restrained.-For members completely restrained to prevent changes in over-all length

$$
L T Z_{s}+\frac{2}{E_{s}} \int_{0}^{L / 2} S d x=0 .
$$

Substituting the value of $S$ from eq 2 and solving for $f_{s}$, gives for the maximum tensile stress in the reinforcement at a crack:

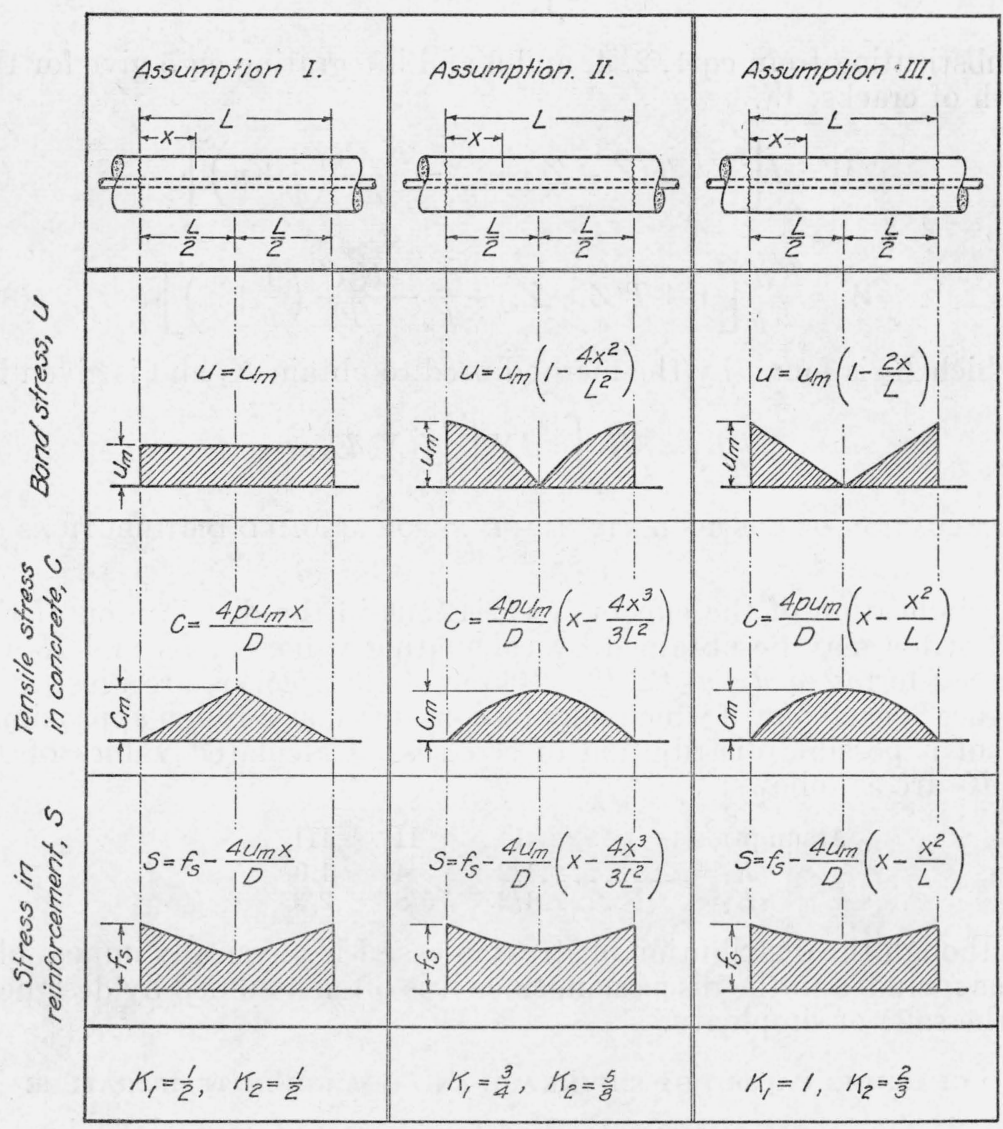

Figure 8.-Assumed distribution of stresses.

Values of the equations for $S, C$, and $u$ are plotted for $0<x<L / 2$.

$$
f_{s}=\frac{K_{2} C_{m}}{p}-E_{s} T Z_{s}
$$

Before cracking, the tensile stress in the concrete is

$$
C=\left(V-T Z_{c}\right) E_{c},
$$

and the concrete cracks when $C$ equals $C_{m}$, the tensile strength.

The minimum spacing of the cracks is given by eq 6 , and the widths of cracks are obtained by substituting the value of $f_{s}$ given by eq 12 in eq 8 a. 


$$
W=\frac{K_{1} D}{R p}\left[V-T Z_{c}-\frac{K_{2} C_{m} n}{E_{s}}\right] .
$$

Obviously, if the reinforcement yields in tension, the width of cracks may become much greater than indicated by eq 13 . Hence, if reinforcement is used to control the widths of cracks, the value of $f_{s}$ given by eq 12 should not exceed the yield strength.

\section{COMMENTS ON THE THEORY}

As indicated in the discussion of the test data, the widths of cracks were found to be proportional to the stress above "the stress at zero width of crack." The stress for zero width of crack corresponds to the quantity $K_{2} C_{m}[(1 / p)+n]$ in eq $8,8 \mathrm{a}$, and 10 and to $K_{2} C_{m} n$ in eq 13. Under the assumptions, $n C_{m}=e E_{s}$ and $C_{m}[(1 / p)+n]=C_{m} / p+$ $e E_{s}$, in which $e$ is the extensibility of the concrete. It is seen that the properties of the concrete affecting the magnitude of the stress at zero width of crack are the tensile strength and the extensibility, the strength being the more important for all but high values of $p$, except in eq 13 for members completely restrained, when only the extensibility governs.

Although the values of tensile strength and modulus of elasticity of concrete cannot be predicted accurately, the stress at zero width of crack is much smaller than the other quantities within the brackets of the equations for width of cracks in most practical cases. Hence, a considerable error in estimating their value has a relatively small effect on the estimate of $W$. Perhaps the largest errors are those in estimates of $n$, as the strains are not proportional to the stresses, as assumed, and the deformations may be increased greatly by creep or plastic flow under sustained stresses. However, these errors may be minimized by selecting the value of $n$ corresponding to the average stress between $x=0$ and $x=L / 2$ and by adjusting $n$ for the effect of creep of the concrete.

Creep in bond (slip under sustained load) decreases the tensile stress in the concrete and increases the width of cracks. The limited information available indicates that the effect of creep in bond is small in comparison with other movements, except when the stresses are large at early ages of concrete and when members reinforced with plain bars are subjected to repeated loading.

In the development of the equations, the effects of shearing deformations in the concrete were disregarded. Because of these deformations, the tensile stress in the concrete is greatest next to the reinforcement, and it decreases with distance from the reinforcement. Accordingly, the tensile resistance of the concrete is less than that indicated by eq 1 ; in effect this is equivalent to reduction in $A_{c}$ or an increase in $p$. The effects of shearing deformations would depend somewhat on the spacing of the cracks and would be greatest when the reinforcement is widely spaced.

The three assumed distributions of bond stress between $x=0$ and $x=L / 2$, illustrated in figure 8 , are rough approximations of those found experimentally under a variety of conditions [1,2,3]. Test data on pull-out specimens indicate that, with a very small slip of the loaded end of the reinforcement, the bond stress is greatest at 
that end. For plain bars, the bond stress at the loaded end increases to a maximum value and then decreases slightly, the plane of maximum bond stress moving toward the unloaded end as the slip continues to increase. With an effectively deformed bar, the maximum bond stress occurs at the loaded end and increases with an increase in slip, reaching much higher values than with smooth bars. Aside from these generalizations, the form of distribution of bond stress is not known, and present knowledge is insufficient to indicate the form most applicable to the present problem.

Before the spacing of cracks has reached the minimum value, there are likely to be lengths between cracks in which the bond stress is zero. The conditions during the early development of cracks were not considered in deriving the equations, but, as previously indicated, the form of the equations for the spacing and width of cracks would not be affected.

The equations show that the spacing and width of cracks are inversely proportional to $R$, the ratio of $u_{m}$ to $C_{m}$. Data showing explicitly how $u_{m}$ varies with $C_{m}$ are not available, but there is some evidence indicating that the departure of the ratio $R$ from a constant is not large for a given type of reinforcement bar used in ordinary concretes containing dense aggregate. Therefore, the value of this ratio depends chiefly on those factors that affect the bond strength with a given concrete. The results of bond tests, especially those of Menzel [4] and Robin et al [5], show that, with all other conditions remaining: constant, the bond strength is greatly influenced by the orientation and position of the reinforcement in the member. Aside from this, it has been repeatedly demonstrated that, for a given slip, the bond strength is much greater with well designed deformed bars than with p'ain bars, indicating that $R$ is correspondingly greater with the deformed bars.

The value of $u_{m}$ of most significance with respect to cracking is the maximum bond stress corresponding to a slip at a crack equal to onehalf of the width of the crack. In tests of ordinary pull-out specimens, only the average stresses for various slips are determined, and this varies with the length of embedment of the reinforcement. Another procedure would be preferable for obtaining quantitative values of $u_{m}$ or $R$. Nevertheless, it seems likely that existing data on bond provide useful estimates on the relative values of $R$ for various types of reinforcement bars.

Repeated applications of the load causing cracks produce some increase in the widths of cracks. This effect is discussed in another section.

\section{COMPARISON OF TEST DATA WITH THEORY}

As previously indicated, the minimum spacing of cracks in the tensile specimens and their width, after the spacing had approached the minimum value, varied approximately as indicated by eq 6 and $8 a$. In particular, the spacing increased with $D / p$ (see eq 6) and was roughly in reverse order to the bonding effectiveness of the bars as determined by pull-out tests. The widths of cracks were linearly related to $L / E_{s}$ and to the stress in the reinforcement at a crack; the "stress at zero width of crack" was greater with the "strong" than with 
the "weak" concrete and decreased with an increase in the ratio of reinforcement.

The degree of concordance between the data and the theory may be judged by comparing the values of $K_{1} / R$ and $K_{2}$ computed from two distinct sets of experimental data independently determined, viz., the values of the spacing of cracks, and their widths. The values of $K_{1} / R$ and $K_{2}$ are given in table 5 , together with the equations used in their evaluation.

TABLE 5.- Experimental values of dimensionless coefficients $K_{1} / R$ and $K_{2}$.

Values were computed from the dimensions of the specimens, properties of the materials, the observed values of the minimum spacing of cracks, $L$, the slope $X$, and the intercept $Y$ of the straight lines shown in figures 3 and 4 , as follows:

Column $2, \frac{K_{1}}{R}=\frac{L p}{D}$, based on spacing of cracks eq 6 .

Column $3, \frac{K_{1}}{R}=\frac{X E_{s} p}{D}$, based on the observed relation between width of cracks and the stress in the reinforce-
ment, eq 8a and $W=X(f .-Y)$. Column $6, K_{2}=\frac{Y}{C_{m}\left(\frac{1}{p}+n\right)}$, based on the "stresses at zero width of crack," eq $8 \mathrm{a}$ and $W=X\left(f_{s}-Y\right)$.

Column 7, $K_{2}=\frac{X Y E_{s}}{L C_{m}\left(\frac{1}{p}+n\right)}$, based on the "stresses at zero width of crack" and the slopes of the stresscrack-width graphs, eq 8 and $W=X\left(f_{\mathrm{s}}-Y\right)$.

\begin{tabular}{|c|c|c|c|c|c|c|c|}
\hline \multirow{2}{*}{ Kind of bar } & \multicolumn{2}{|c|}{$K_{1} / R$} & \multirow{2}{*}{$\begin{array}{c}K_{1} / R, \\
\text { average }\end{array}$} & \multirow{2}{*}{ 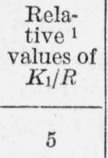 } & \multicolumn{2}{|c|}{$K_{2}$} & \multirow{2}{*}{$\begin{array}{c}K_{2}, \\
\text { average }\end{array}$} \\
\hline & 2 & 3 & & & 6 & 7 & \\
\hline $\begin{array}{l}\text { 7/8-in. plain } \\
7 / 8 \text {-in. deformed.... } \\
\text { Two 5/8-in. deformed } \\
\text { No.8 Isteg. } \\
\text { 7/8-in. threaded. }\end{array}$ & $\begin{array}{l}0.53 \\
.36 \\
.34 \\
.32 \\
.23\end{array}$ & $\begin{array}{l}0.59 \\
.40 \\
.37 \\
.34 \\
.23\end{array}$ & $\begin{array}{l}0.56 \\
.38 \\
.36 \\
.33 \\
.23\end{array}$ & $\begin{array}{l}1.00 \\
.68 \\
.64 \\
.59 \\
.41\end{array}$ & $\begin{array}{l}0.65 \\
.56 \\
.46 \\
.50 \\
.39\end{array}$ & $\begin{array}{l}0.71 \\
.61 \\
.51 \\
.52 \\
.39\end{array}$ & $\begin{array}{l}0.68 \\
.59 \\
.48 \\
.51 \\
.39\end{array}$ \\
\hline
\end{tabular}

${ }^{1}$ Considering $K_{1} / R=1$ for the $7 / 8$-in. plain bar.

The two values of $K_{1} / R$ for each type of bar, one (col. 2) computed from measured values of the spacing and the other (col.3) from the observed relations between the stress in the reinforcement and the width of cracks, were within 6 percent of the average (col. 4). Similarly, the values of $K_{2}$ for each type of bar, computed from the observed "stress at zero width of crack" (col. 6) and those computed from the observed slopes of the stress-crack width graphs and the spacing (col. 7), also were within 6 percent of the average (col. 8). Considering the large dispersion of most data obtained in tensile and bond tests of concrete, these results indicate a fair correspondence between the data and the theoretical relation between the spacing and the width of cracks. Some of the other relations indicated by the theory are not so well supported by the experimental data.

The average values of $K_{1} / R$ with the "strong" concrete was $5 \frac{1}{2}$ percent greater than with the "weak" concrete, which is hardly a significant difference. The values for the 5 -in. cylinders averaged 15 percent less than for the 4-in. cylinders, indicating that the spacing of cracks decreased somewhat less rapidly than $D / p$. However, for two types 
of bars $K_{1} / R$ was slightly larger, indicating that the departure from direct proportionality between the spacing and $D / p$ may not be significant.

The relative values of $K_{1} / R$ given in table 5 are roughly in the same order as the values of the ratios of the tensile strengths of the concretes to the bond strengths in table 4 . These data on bond strength are not concordant, in that the bond stresses were in many instances larger with the "weak" than with the "strong" concrete, and the effect of the direction of placing the concrete with respect to the direction of pull was not consistent. Moreover, the different bars were not rated in the same order for the several given values of slip at the free end of the pull-out specimens. The reasons for the discrepancies are not known, but it is clear that the data do not afford a satisfactory means for checking the relations between values of $R$ based on the results of bond tests and those computed from data on the spacing and width of cracks.

According to the analysis, the value of $K_{2}$ depends only on the distribution of the bond stress with a given type of bar. The variations of $K_{2}$ with the strength of the concrete and with the ratio of reinforcement observed experimentally may be largely the result of chance, as the computed values of $K_{2}$ depended on the extrapolated values of "stress at zero width of crack," which showed large dispersions for similar specimens. However, there are other possible causes of the variations, a consideration of which justifies doubt as to their general significance. The average value of $K_{2}$ with the 4 -in. cylinders was 0.51 and with the 5 -in. cylinders was 0.54 . This difference may have resulted from a difference in the distribution of bond stresses and from the more pronounced effects of slight eccentricities of loading on the smaller cylinders. But a part of it may have been caused by ignoring the effect of shrinkage of the concrete prior to the loading. If shrinkage occurred before the tests, all of the values of $K_{2}$ in table 5 are somewhat lower than the true values. And, making allowance for a shrinkage of less than 0.005 percent would result in equalizing the values of $K_{2}$ for the 4 -in. and the 5 -in. cylinders.

With the "weak" concrete the average value of $K_{2}$ was 0.58 and with the "strong" it was 0.48. Again, a small shrinkage of the specimen before testing, ignored in computing the values of $K_{2}$ from the data, would cause both values to be too low, but the effect of shrinkage presumably would be greater for the richer "strong" concrete. However, there is another reason for believing that the large difference in the values of $K_{2}$ with the two concretes may not be typical of concretes in general. The tensile strength of the "weak" concrete was less and that of the "strong" concrete was more than for typical concretes of the compressive strengths given in table 2. Values from a larger number of tests of gravel-aggregate concretes tested by others indicate a ratio of $270: 420$ instead of $250: 450$ for the tensile strengths of concretes having compressive strengths in the proportion 2900:5300 (table 2). The extensibility, $e$, of the concretes, estimated from measured strains in the reinforced tensile specimens, were 110 and 135 millionths, respectively, for the "weak" and the "strong" concretes. Values of $K_{2}$ computed by means of the equations of table 5 , after substituting $e E_{c}$ for $C_{m}$, are nearly equal. Therefore, there is not clear evidence that the values of $K_{2}$ are importantly affected by changes in the strength of the concrete. 
The values of $K_{2}$ were consistently less with the deformed and Isteg bars than with the plain bar and were lowest with the threaded bar. The differences in the average values are too large to be attributed to chance, and they seem too large to be simply the result of different forms of distribution of the bond stresses. Possibly slip occurred at an early age as the result of differential volume changes of the concrete and reinforcement, the slip being greater with the plain than with the deformed bars and least with the threaded bar. However, if it were assumed that the concrete slipped freely on the plain bar and did not slip on the threaded bar, a shrinkage of 0.011 percent of the "weak" concrete and 0.016 percent of the "strong" concrete would be required to account fully for the differences in the values of $K_{2}$. As the plain bars are known to offer some resistance to slip and as these values for shrinkage are much larger than seem likely, for the type of curing employed, it is evident that shrinkage and slip are not entirely responsible for the differences in the values of $K_{2}$. Another possible cause for the values of $K_{2}$ being lower with bars having rough surfaces is the effect of the roughness in forming discontinuities in the surface of the concrete in contact with the bars, these resulting in a lower tensile resistance of the concrete and correspondingly lower values for the "stress at zero width of crack." Of the three factors-distribution of bond stress, differential shrinkage and slip, and discontinuities in the concrete surfaces in contact with the reinforcement-which may have caused the values of $K_{2}$ to decrease with an increase in the surface roughness of the reinforcement, the last named seems the most important.

In summary, the simple theory did not account fully for the factors controlling the spacing and width of cracks. In particular, the values of $K_{2}$ were dependent upon the shape of the reinforcement and the results of conventional pull-out tests did not provide information for making reliable estimates of $R$ and $K_{2}$. Although there were other differences between the theory and the data on spacing and width of cracks, these were too small to be positively significant in view of the possible effects of factors ignored when comparing the data with the equations.

\section{COMPARISON WITH PREVIOUS WORK}

Most of the previous investigations of tensile cracking of reinforced concrete dealt with the cracking of flexural members or with the significance of cracks. As these subjects are outside the scope of this paper, the following review cites only the investigations giving information on the factors governing the spacing and width of cracks.

In tests of members subjected to a uniform bending moment over a considerable length, Considerre [6] found that, when the ratio of reinforcement was the same, the spacing of cracks increased with the diameter of the reinforcement. Similar tests by Bach and Graf [7] confirmed the findings of Considère and showed that the width of cracks was less when the surface of the reinforcement was rough than when it was smooth. For a range of loading between the design load and that causing yielding of the reinforcement, the widths of cracks were roughly proportional to the spacings. These investigators, as well as Berry [8], Slater [9, 10, p. 421], and Probst [11], found that, under the usual conditions of service, the number of cracks is 
increased slightly and the width considerably by repeated loading. The increases were greatest for the first few repetitions, after which the number and width of cracks changed by only small amounts. More recent investigations [12, p. 186] indicate that the increase in width of cracks under repeated loads is much smaller with deformed bars than with plain bars.

Taylor and Thompson [13, p. 565-69] report an analysis of the stresses in symmetrically reinforced concrete members caused by shrinkage and change in temperature and showed that the spacing of cracks is proportional to $D / p$. They pointed out that reinforcement which provides a mechanical bond is more effective than smooth bars in distributing and controlling the width of cracks.

Slater $[10$, p. 461] measured the widths of cracks in the webs of heavily reinforced beams subjected to high shearing stresses. The widths were approximately proportional to the increase of load beyond that causing the cracking. The rate of increase of width with increasing load was substantially independent of the strength of the concrete, but was roughly proportional to the width of the web (or to $1 / p$ ). The extrapolated value for the stress at zero width of crack was approximately proportional to a quantity closely similar to $C_{m}[(1 / p)+n]$, expressed in terms of the compressive strength of the concrete and the width of the web.

Kuznetsov [14] measured spacing and width of cracks in centrally reinforced cylinders in tension and also presented a theoretical analysis of the distribution of stresses in the test specimens. The width and spacing of cracks decreased as the bonded surface of steel and the percentage of reinforcement increased, and repeated application of load caused considerable additional widening of cracks. Equations for distribution of bond stress and the width of cracks were obtained by the author. The equations were derived by consideration of equilibrium of a centrally loaded reinforced cylinder and the basic assumption that the bond stress was proportional to the quantity $\left(f_{s} / E_{s}\right)-\left(C / E_{c}\right)$.

A theoretical analysis of stresses in a straight, symmetrically reinforced prism produced by shrinkage and change in temperature was reported by Vetter [15]. Equations, based upon a constant bond stress along the reinforcement, were given for the spacing of cracks and the stresses in the concrete and reinforcement. Vetter's equation for the minimum spacing of cracks corresponds to eq 6 with $K_{1}=1 / 2$. Other equations are given for calculating the minimum amount of reinforcement to avoid overstressing, for determining the maximum volume change before overstressing and for estimating the spacing of cracks during the early stages of cracking.

In a discussion of Vetter's paper [15, p. 1070] Lester L. Meyer gave data on the spacing and width of cracks in 11 reinforced-concrete slabs tested in tension. The reinforcement in the slabs ranged from 0.25 to 1.50 percent. Sufficient information on the conditions is not given for an estimate of the effects of volume changes on the measured widths of the cracks, and the spacings were somewhat erratic. However, the median value of $K_{1} / R$, computed from the data on the minimum spacing, is 0.37 , the same as the average value for the deformed bars used in this investigation. 
Thomas [16] reported on an investigation of cracking caused both by volume change and strain, the value of prestressing as a preventive and the practical significance of cracks. Equations were given for estimating the stresses caused by shrinkage, taking into account the effects of creep and the degree of restraint. Data and discussion indicate that resistance to cracking of completely restrained members was influenced by the kind of aggregate and is greater with slow hardening than with rapid hardening cement. The resistance to shrinkage cracking was not affected appreciably by variations in the amounts of cement or mixing water in the concrete. Equations for the spacing and width of cracks were based upon a parabolic distribution of bond stress (assumption II of this paper). Data obtained by testing beams were in good qualitative agreement with the equations. Observations showed that cracks tended to close upon releasing loads, but that the resistance to slip delayed this movement until the loads were considerably reduced. Under sustained loads, the widths of cracks in the beams increased about 50 percent, reaching constant values in a few weeks.

Several authors of papers published in the Preliminary Publication of the Second Congress of the International Association for Bridge and Structural Engineering (1936) discussed the significance of cracking, and some of them (other than Thomas) gave data on the factors affecting the spacing and width of cracks. Bornemann (p. 185, et seq.) reviewed data indicating that, with smooth bars as reinforcement, high stresses and repeated loading breaks down resistance to slipping, resulting in an increase in width but not in number of cracks. He states that, when a crack forms, the dynamic effect of the sudden release of tension in the concrete increases the initial width of the crack, this effect being most pronounced with low ratios of reinforcement and concrete of high tensile strength. He concludes that widths of cracks may be minimized by the use of a slow hardening concrete with small shrinkage and slow drying and of small bars with rough surfaces. Colonnetti (p. 191) proves by a theoretical analysis that it is preferable to use a large number of small bars than a smaller number of large ones. Saliger (p. 293) discussed the mechanism of the cracking of reinforced-concrete members, especially beams, gave data on the stress in the reinforcement when the first crack appeared in beams and developed equations for the spacing of cracks based on assumption III of this paper. The advantage of using a large number of small bars with rough surfaces was stressed.

In summary, the previous investigations reviewed give but little quantitative data on the spacing and width of cracks, but the information available indicates that the widths of cracks are roughly proportional to $D / p$, the rate of increase of width with increase of stress is independent of the strength of the concrete and the stress at zero width of crack is roughly proportional to the strength of the concrete. Reinforcement which provides a mechanical bond not only is more effective than smooth bars in controlling the initial widths of cracks, but also in minimizing the enlargement caused by sustained or repeated loads. The indications of the test data and of the analysis given in this paper are in agreement with the findings in earlier investigations as to the factors controlling the spacing and width of cracks. 


\section{PRACTICAL APPLICATIONS}

Ordinarily, when it is desired to estimate the probable spacing and width of cracks in reinforced concrete, precise information is not available on the properties of the concrete and the other factors controlling cracking. Consequently, refinements in the equations used in making the estimates are not warranted, and it is convenient to reduce to a minimum the number of quantities to which values must be assigned before numerical solutions are obtained. According to the data of table 5 (col. 4), eq 6 , giving the minimum spacing of cracks, may be simplified to read

for the plain bar, and

$$
L=0.6 D / p
$$

for the deformed bars.

$$
L=0.4 D / p
$$

Available information on the tensile properties of concretes of ordinary compositions indicates that the value of $n C_{m}$ from eq 8 a, et seq., depends in part on the rate of stressing the concrete and that, except for concrete subjected to high stress at an unusually early age or to unusual storage conditions, the value ranges between 3,000 and 5,000 $\mathrm{lb} / \mathrm{in} .^{2}$, being near the lower value in conventional laboratory load tests and near the upper value when the stresses are developed slowly. In most practical cases, $n C_{m}$, is not a large part of the total magnitude of the quantity within the brackets of an equation for the width of cracks, and a value of $4,000 \mathrm{lb} / \mathrm{in} .^{2}$ for $n C_{m}$ may be assigned tentatively Using this approximation, eq 8 a for the width of cracks in symmetrically reinforced members subjected to tensile forces may be modified to read

$$
W=\frac{K_{1}}{R} \frac{D}{E_{s}^{\prime} p}\left[V E_{s}+T\left(Z_{s}-Z_{c}\right) E_{s}+f_{s}-K_{2}\left(\frac{C_{m}}{p}+4,000\right)\right]
$$

By setting $f_{s}=0$, eq 15 applies to nonrestrained members subjected to shrinkage and change in temperature.

For members fully restrained

$$
W=\frac{K_{1}}{R} \frac{D}{E_{s} p}\left[V E_{s}-7 Z_{c} E_{s}-4,000 K_{2}\right] .
$$

The amount of reinforcement needed to prevent stressing the reinforcement beyond the yield point is, from eq 12,

$$
p>\frac{K_{2} C_{m}}{Y+E_{s} T Z_{s}}
$$

in which $Y$ is the yield point of the reinforcement.

The approximate values of the coefficients indicated by the data of table 5 are $K_{1} / R=0.6$ and $K_{2}=2 / 3$ for the plain bar, and $\bar{K}_{1} / R=0.4$ and $K_{2}=1 / 2$ for the deformed bars.

When the serviceability of a structure is likely to depend importantly upon the width of the tensile cracks, it is obviously desirable to make the fullest possible use of existing knowledge on methods of minimizing the effects of shrinkage of concrete. The methods of controlling cracking, such as limiting the allowable tensile stress to a value less than that based on consideration of strength, are well known 
and are commonly employed, but the choices of materials and design stresses usually are governed by other factors, and, to attain the greatest economy in the use of reinforcement, it is essential that design stresses be as large as are deemed safe. The advantage of using bars of the smallest feasible sizes to give low values of $D / p$ also is well known, but limitations of space often prevent the placing of large number of small bars. Then, the use of reinforcement providing a low value of $K_{1} / R$ is especially advantageous.

Results of other bond tests $[17,18,19]$ indicate that the particular type of deformed bars used in these tests afford higher bond strengths than most of the present-day commercial deformed bars. It would be expected, therefore, that the value of $K_{1} / R$ for most reinforcement bars would have exceeded 0.4 , and for some approached 0.6 , the value found for the plain bar. Moreover, investigations [17, 18, 19] indicate that $K_{1} / R$ for some experimental deformed bars probably is less than 0.2 , the value found for the threaded bar. As the enlargement of cracks under prolonged or repeated loading has been found to be greater with plain than with deformed bars, the actual practical advantage of a well designed deformed bar probably is greater than indicated by these tests. The development and use of a type of reinforcement bar that would assure a low value of $K_{1} / R$ offers promise of more reliable bond and anchorage of reinforcement, better control of the width of cracks and more economical use of steel reinforcement. The recommendations of Abrams [20] and Menzel [19] appear to be satisfactory guides for the design of such a bar.

\section{SUMMARY OF RESULTS}

1. Widths of tensile cracks interpolated to correspond to specimens with equal percentages of reinforcement were least for specimens reinforced with pairs of $5 / 8$-in. deformed bars or with a $7 / 8$-in. threaded bar. The relative values of the widths of cracks at a stress of 30,000 $\mathrm{lb} /$ in. $^{2}$, representing two percentages of reinforcement and concretes of two strengths, are given in the following table.

Type of bar

Ratio of width of cracks to that observed for 7/8-in plain hot-rolled

7/8-in. plain hot-rolled

1. 00

$7 / 8$-in. deformed

0. 72

No. 8 webbed Isteg

$7 / 8$-in. threaded

.75

.48

.46

2. For the width of crack observed in specimens reinforced with plain hot-rolled bars carrying a stress of $20,000 \mathrm{lb} / \mathrm{in}^{2}{ }^{2}$, the corresponding stresses for the other bars were, on the average, $24,000 \mathrm{lb} / \mathrm{in}^{2}{ }^{2}$ with the Isteg bars, $25,000 \mathrm{lb} /$ in. $^{2}$ with the $7 / 8$-in. deformed bars, and 35,000 $\mathrm{lb} / \mathrm{in}^{2}{ }^{2}$ with the threaded and the $5 / 8$-in. deformed bars.

3 . There was no significant difference between the widths of cracks for a given stress and a given type of bar, as observed in specimens of "weak" and "strong" concrete.

4. The widths of cracks observed in cylinders of the same diameter, and for different bars stressed to the same extent, varied linearly with the spacing of cracks observed for the different bars. This observa$531781-43-4$ 
tion is true only for reinforcement bars having nearly the same modulus of elasticity.

5 . The test data and the theoretical equations were in good agreement with respect to the effects of the principal factors controlling the spacing and width of cracks. The values of the coefficient which determine the "stress at zero width of crack" were markedly affected by changes in the shape of the reinforcement bar.

6 . The width of cracks in symmetrically reinforced-concrete members subjected to axial tension and to the effects of shrinkage of concrete and change in temperature may be minimized by:

(a) Using concrete of low shrinkage properties.

(b) Limiting tensile stresses in the reinforcement to low values.

(c) Reinforcing the concrete with the largest number of bars of the smallest sizes compatible with other requirements.

(d) Using deformed bars having projecting lugs that afford resistance against slipping without causing splitting of the concrete and that are spaced to provide the minimum of bearing area necessary to develop the desired bond strength.

\section{REFERENCES}

[1] W. H. Glanville, Bond Resistance, Technical Paper No. 10, Building Research Board, Great Britain (1930).

[1a] L. Schuman and John Tucker, Jr., Tensile and other properties of concretes made with various types of cement. J. Research NBS 31. (Publication pending.)

[2] D. Watstein, Bond stress in concrete pull-out specimens. J. Am. Concrete Inst. 38, 37 (1941).

[3] H. J. Gilkey, S. J. Chamberlin, and R. W. Beal, Bond Between Concrete and Steel, Iowa Eng. Exp. Sta. Bul. 147 (1940).

[4] C. A. Menzel, Some factors influencing results of pull-out bond tests, Proc. Am. Concrete Inst. 35, 517 (1939).

[5] R. C. Robin, P. E. Olsen and R. F. Kinnane, Bond strength of reinforcing bars embedded horizontally in concrete, Trans. Inst. Engrs. (Australia) 14, 201 (Sept. 1942).

[6] A. Considère, Handbuch für Eisenbetonbau, 3d ed., p. 104 (1921).

[7] C. Bach and O. Graf, Handbuch für Eisenbetonbau, 3d ed., p. 105 (1921).

[8] H. C. Berry, Some tests of reinforced concrete beams under oft-repeated loading, Am. Soc. Testing Materials 8, 454 (1908).

[9] W. A. Slater, G. A. Smith, and H. P. Mueller, Effect of repeated reversals of stress on double-reinforced concrete beams, Tech. Pap. BS 14 (1921) T182.

[10] W. A. Slater, Shear tests of reinforced concrete beams, Tech. Pap. BS 20 (1926) T314.

[11] E. Probst, The influence of rapidly alternating loading on concrete and reinforced concrete, Struc. Engr. 9, 410 (1931).

[12] E. Bornemann, Tensile strength and formation of cracks in concrete, Prelim. Pub. Second Cong. Int. Assn. for Bridge and Struc. Eng. (1936).

[13] Taylor and Thompson, Concrete, Plain and Reinforced, 3d ed. (1916).

[14] A. N. Kuznetsov, Formation of cracks in centrally loaded reinforced concrete specimens, Stroitel'naya Promyshlennost', U. S. S. R., 18, 42 (July 1940).

[15] C. P. Vetter, Stresses in reinforced concrete due to volume changes, Trans. Am. Soc. Civil Engrs. 98, 1039 (1933).

[16] F. G. Thomas, Cracking in reinforced concrete, The Struc. Engr. 15, 298 (1936); and Prelim. Pub. Second Cong. Int. Assn. for Bridge and Struc. Eng. p. 223 (1936).

[17] C. J. Posey, Tests of Anchorages for Reinforcing bars, Bul. 3, University of Iowa Studies in Engineering (1933).

[18] G. R. Wernisch, Bond studies of different types of reinforcing bars, Proc. Am. Concrete Inst. 34, 145 (1938).

[19] C. A. Menzel, A Proposed Standard Deformed Bar for Reinforcing Concrete, Proc. 17th Semiannual Meeting Concrete Reinforcing Steel Inst. (1941).

[20] D. A. Abrams, Tests of Bond Between Concrete and Steel, Bul. 71, Univ. of Ill. Eng. Exp. Sta. (1913), p. 212, par. 21.

Washington, May 6, 1943. 